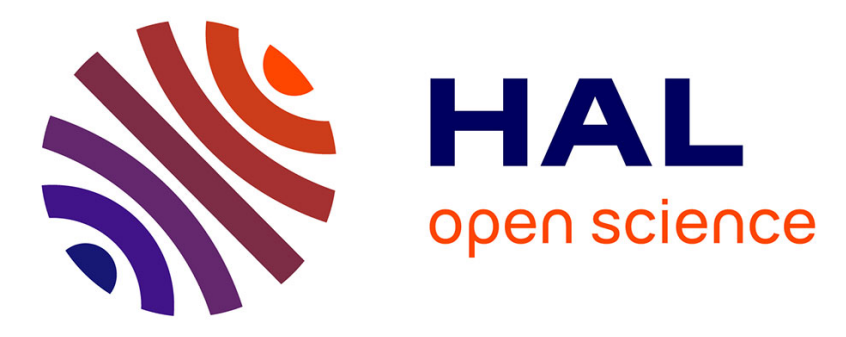

\title{
Gadolinium-based nanoparticles for theranostic MRI-radiosensitization
}

François Lux, Lucie Sancey, Andrea Bianchi, Yannick Crémillieux, Stéphane Roux, Olivier Tillement

\section{- To cite this version:}

François Lux, Lucie Sancey, Andrea Bianchi, Yannick Crémillieux, Stéphane Roux, et al.. Gadoliniumbased nanoparticles for theranostic MRI-radiosensitization. Nanomedicine, 2015, 10 (11), pp.18011815. 10.2217/NNM.15.30 . hal-01275075

\section{HAL Id: hal-01275075 \\ https://hal.science/hal-01275075}

Submitted on 18 Feb 2016

HAL is a multi-disciplinary open access archive for the deposit and dissemination of scientific research documents, whether they are published or not. The documents may come from teaching and research institutions in France or abroad, or from public or private research centers.
L'archive ouverte pluridisciplinaire HAL, est destinée au dépôt et à la diffusion de documents scientifiques de niveau recherche, publiés ou non, émanant des établissements d'enseignement et de recherche français ou étrangers, des laboratoires publics ou privés. 


\section{Gadolinium-based nanoparticles for theranostic MRI-radiosensitization}

\begin{abstract}
A rapid development of gadolinium-based nanoparticles is observed due to their attractive properties as MRI-positive contrast agents. Indeed, they display high relaxivity, adapted biodistribution and passive uptake in the tumor thanks to enhanced permeability and retention effect. In addition to these imaging properties, it has been recently shown that they can act as effective radiosensitizers under different types of irradiation (radiotherapy, neutron therapy or hadron therapy). These new therapeutic modalities pave the way to therapy guided by imaging and to personalized medicine.
\end{abstract}

\section{Keywords: gadolinium $\bullet$ MRI $\bullet$ multimodality $\bullet$ nanoparticles $\bullet$ oncology $\bullet$ radiotherapy - theranostic}

Based on a fruitful interaction between various scientific fields (chemistry, physics, biology and medicine among others), the intense research activity devoted to nanotechnologies led to the development of multifunctional nanoparticles adapted to many different applications [1,2] in energy [3], electronics $[4,5]$, catalysis [6], agriculture [7], health and medicine $[8-10]$. More specifically, nanoparticles are a class of materials with at least one dimension below $100 \mathrm{~nm}$ (this range can be extended up to $1000 \mathrm{~nm}$ in the literature) $[11,12]$. They display interesting properties for medical applications as new physical properties at the nanoscale [13-15]; high surface to volume ratio inducing chemical reactivity different from bulk materials and possibility to gather considerable amounts of imaging or therapeutic agents [16]; possibility to gather different imaging and/or therapeutic agents in a single object for multimodal applications [17] and possibility to finely tailor their size, shape and surface to modulate their biodistribution $[18,19]$. Among the different medical applications proposed by nanotechnology, theranostic (i.e., combination of therapeutic and diagnostic applications) is one of the most exciting $[20,21]$. In this rapidly growing field, a particular interest has been focused on magnetic nanoparticles [22,23]. In the case of magnetic nanoparticles for applications in oncology, MRI is the principal modality of imaging. It can be coupled with computed tomography (CT) [24], fluorescence imaging [25,26], PET [27] or single photon emission computed tomography (SPECT) [28,29] for multimodal imaging. For the therapeutic part, magnetic nanoparticles are proposed for drug delivery [30], phototherapy [31], photodynamic therapy [32] and radiotherapy [33,34]. Radiotherapy is of particular interest in the context of theranostic applications because it is the most commonly used nonsurgical therapy [35] and will benefit greatly from the contribution of imaging.

Strategies are now developed to include PET/SPECT and/or MRI for the individualization of treatment by radiotherapy, the assessment of treatment and the follow-up after treatment $[36,37]$. For such treatments, the development of compounds that can effectively be used as both imaging agents and radiosensitizers (i.e., compounds that can enhance the effect of radiotherapy) [38] could be a real progress. Most of the radiosensitizers tested actually are composed of elements with high atomic number $(Z)$ which display significantly higher mass
François Lux*,1, Lucie Sancey ${ }^{1}$, Andrea Bianchi², Yannick Crémillieux², Stéphane Roux ${ }^{3}$ \& Olivier Tillement ${ }^{1}$ 'Institut Lumière Matière, UMR5306 Université Lyon 1-CNRS, Université de Lyon, 69622 Villeurbanne cedex, France ${ }^{2}$ Centre de Résonance Magnétique des Systèmes Biologiques, CNRS UMR5536, Université Bordeaux, Bordeaux, France ${ }^{3}$ Institut UTINAM, UMR6213 UFC-CNRS, Université de Franche-Comté, Besançon cedex, France

*Author for correspondence: francois.lux@univ-lyon1.fr 
energy absorption properties in comparison with soft tissues [39,40]. Some classical molecular contrast agents based on iodine, gadolinium and some molecular anticancer drugs (e.g., cisplatin) have been already tested for radiosensitization [41]. Owing to their capability to contain greater amount of high $\mathrm{Z}$ elements, radiosensitizing nanoparticles received much attention. The pioneering work of Hainfeld et al. [38] revealed that gold nanoparticles behave as efficient radiosensitizers due to the high atomic number of gold $(Z=79)$, their easy synthesis and relatively safe in vivo behavior [42-44]. However promising radiosensitizing nanoparticles can also be obtained with other high $\mathrm{Z}$ elements. Among them, gadolinium $(Z=64)$ appears very attractive for designing nanoparticles, which behave both as radiosensitizers and MRI contrast agents. This review aims therefore at describing gadolinium-based nanoparticles for biomedical applications and more specifically for MRI coupled to radiotherapy.

\section{Interest of gadolinium for medicine}

Gadolinium is the most well-known lanthanide element for medical applications. Its most common oxidation state is +III as other lanthanides; it is considered as a hard acid and displays large coordination numbers $(8-10)$ [45]. Its use in medicine is directly correlated to the development of MRI and to the development of contrast agents for this imaging modality. More than 10 million MRI studies use gadolinium per year [46,47]. The choice of gadolinium (III) for MRI applications can be explained by its seven unpaired electrons (most paramagnetic stable ion) and its slow electronic relaxation [48]. The contrast agents based on gadolinium are mainly small chelates (like DOTAREM, Guerbet or MAGNEVIST ${ }^{\circledR}$, Bayer Healthcare) used as positive contrast agents [49]. Unfortunately, small chelates display relatively low relaxivities (Table 1).

Research on gadolinium-based positive contrast agent for MRI focused mainly on increasing longitudinal relaxivity. Two major approaches [47,50] have been proposed to fulfill this goal: increasing the number of gadolinium units per object, for example, by incorporating the chelates in polymers [51], dendrimers [52], nanogels [53] or nanoparticles [54]; and optimizing the chemical structures of the chelates, essentially by increasing the rotational correlation time [48,55]; this can be achieved by enhancing the mass and the rigidity of the structure. Nanotechnologies are particularly interesting for these two approaches because many gadolinium chelates can be fixed on rigid and heavy structures leading to high $\mathrm{r}_{1}$ objects.

Besides their use for imaging applications, gadolinium-based compounds are also envisaged for therapeutic applications. In fact, gadolinium displays relatively high atomic number $(Z=64)$ and can thus interact with many types of radiations ( $x$ - or gamma-rays, neutrons, electrons and hadrons, among others) [56]. Although this interaction can be used for CT imaging [57], its real interest lies in radiosensitization as shown first for molecular compounds. A molecular gadolinium texaphyrin complex, motexafin gadolinium (III) is currently undergoing a clinical trial for its radiosensitizing properties (Figure 1) [58]. Among the different lanthanides, gadolinium is also of particular interest for neutron capture therapy due to the high neutron capture cross section of nonradioactive ${ }^{157} \mathrm{Gd}$ (2.55.10 barns) $[59,60]$.

Despite these advantages for clinical applications, gadolinium has to be administrated carefully because of the similar ionic radii between gadolinium (III) and calcium (II) that can lead to potential replacement of calcium by gadolinium in some calcium (II) binding sites. As recently emphasized by different publications, the release of free gadolinium (III) can be responsible of nephrogenic systemic fibrosis [61,62]. This disease observed on patients with renal failure that have received gadolinium-based contrast agents seems to be due to the release of gadolinium from acyclic chelates in the acidic conditions of the kidneys. When developing new compounds based on gadolinium, a specific attention has to be paid on this problem. The most used solution is the chelation of gadolinium by macrocyclic ligands like, for example, DOTAREM ${ }^{\circledR}$ (Guerbet) or ProHance ${ }^{\circledR}$ (Bracco SpA) that are based on 1,4,7,10-tetraazacyclododecane-1,4,7,10-tetraacetic (DOTA) derivatives.

\section{Nanoparticles made of gadolinium for MRI}

Due to the interest of gadolinium essentially for MRI, many types of nanoparticles, often multimodal, have

\begin{tabular}{|c|c|c|c|c|}
\hline Contrast agent & $\begin{array}{l}\text { MAGNEVIST }^{\circledR} \text { (Bayer } \\
\text { Healthcare) }\end{array}$ & $\begin{array}{l}\text { DOTAREM }^{\circledR} \\
\text { (Guerbet) }\end{array}$ & $\begin{array}{l}\text { OMNISCAN }^{\circledR} \text { (GE } \\
\text { Healthcare) }\end{array}$ & Prohance $^{\circledR}$ (Bracco SpA) \\
\hline$r_{1}$ & 3.4 & 3.4 & 3.9 & 3.7 \\
\hline$r_{2}$ & 3.8 & 4.8 & 4.3 & 4.8 \\
\hline
\end{tabular}




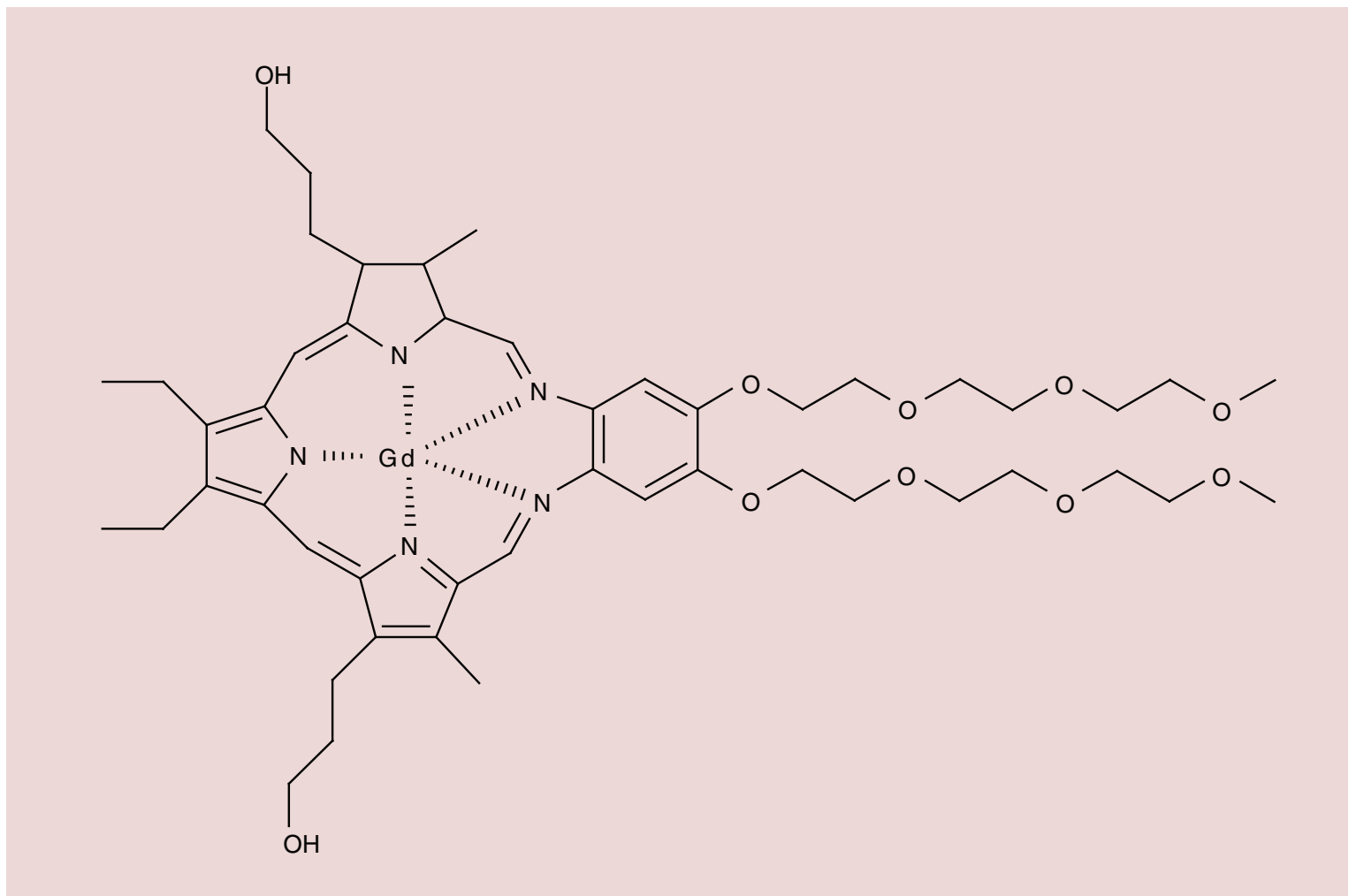

Figure 1. Structure of motexafin gadolinium (III).

Data taken from [58].

been proposed. Two different types of nanoparticles will be discussed in this review. The first one is based on architectures already considered for medical applications on which gadolinium chelates are grafted or into it they are loaded in. The second one is constituted of hybrid core shell nanoparticles made of a crystalline core based on gadolinium or doped with gadolinium.

\section{Nanoparticles functionalized by gadolinium chelates}

The first interest of grafting gadolinium chelates on nanoparticles is to increase the $r_{1}$ per gadolinium ion. Many publications focused on the study of the nuclear magnetic relaxation dispersion profile and on the optimization of the architectures to obtain higher $r_{1}$ at different magnetic fields. As recently reviewed by Botta et al. [55] and Davis et al. [63], gadolinium chelates have been grafted on polymers, dendrimers, liposomes, micelles, gold or silica nanoparticles. In almost all the cases, the same pattern of nuclear magnetic relaxation dispersion profile is observed with an important enhancement of the relaxivity for the average magnetic fields and relaxivity values relatively low at high fields. Gadolinium can also be loaded as cargos into adapted nano-objects such as mesoporous silica, carbon nanotubes or liposomes. In this case, Decuzzi et al. [54] have also shown that geometrical confinement of gadolin- ium chelates can drastically increase their longitudinal relaxivity.

In addition to overcome the low relaxivity of gadolinium chelates, the grafting on nanoparticles significantly increases the short half-lives of the chelates in the body [64]. However for clinical use, the size of the nanoparticles has to be maintained relatively small to limit the toxicity due to poor renal clearance. A hydrodynamic diameter below $6 \mathrm{~nm}$ is generally recommended to allow complete and exclusive renal elimination after intravenous injection as first published by Frangioni $e t$ al. for quantum dots [65,66]. To achieve this, our group has recently proposed a new type of nanoparticle called AGuIX, based on a polysiloxane core and surrounded by DOTA $(\mathrm{Gd})$ derivatives covalently grafted to the inorganic matrix [67]. These nanoparticles display hydrodynamic diameter of 3 $\mathrm{nm}$, mass of $8.5 \mathrm{kDa}$ and longitudinal relaxivity of 6.0 $\mathrm{mM}^{-1} \cdot \mathrm{s}^{-1}$ at $7 \mathrm{~T}$ twice the value of the commercial agent DOTAREM. The small size is obtained by a top down process. First, a gadolinium oxide core is synthesized, then encapsulated in a thin polysiloxane shell (sol gel process) and finally chelates are covalently grafted to the inorganic matrix. During the transfer to water, dissolution of the gadolinium oxide core is observed and gadolinium is chelated by the ligands leading to the final AGuIX nanoparticles. Owing to the pres- 
ence of gadolinium chelates, the excretion mode can be monitored by MRI after intravenous injection of the nanoparticles in rodents. The data collected from MRI clearly showed that the removal of the nanoparticles from body rests on an exclusive renal elimination. These results have been confirmed by the labeling of the nanoparticles by indium-111 and the following of the nanoparticles after intravenous (iv.) injection by SPECT. Moreover the behavior of the nanoparticles in the kidneys has been precisely followed by means of laser-induced breakdown spectroscopy performed on the tissues after sacrifice of the animals (Figure 2) [68].

Another advantage of AGuIX gadolinium-based ultra-small nanoparticles is for lung imaging as recently illustrated. In behalf of their hydrodynamic diameter close to $3 \mathrm{~nm}$, the nanoparticles can pass from the pulmonary airways to the blood circulation before elimination by the kidneys. The biodistribution can be followed by MRI using ultra-short echo time sequences [69]. Acute toxicological study shows almost no inflammation after administration of the nanoparticles by the airways [70]. An interesting application of the administration of the AGuIX nanoparticles is the noninvasive detection of nonsmall-cell lung cancer by MRI (Figure 3) [71]. This easy and reproducible method of administration permits a better visualization of the lung tumors in comparison with intravenous injection. When the nanoparticles are administered by airways, their passage to the blood circulation is faster from the healthy lung tissues than from tumor tissues.

In addition to the development of more effective positive contrast agents, some studies are performed to develop multimodal imaging agents. Multimodal imaging has been developed to propose a better diagnostics by combining the advantages of different imaging modalities [72]. Since the beginning of the 2000s, different bimodal apparatus are available on the clinical market (PET/CT, SPECT/CT, PET/MRI) or for small animals [73]. The arrival on the market of such apparatus is accompanied by the development of many different multimodal agents and in particular of nanoparticles-based contrast agents. Two main types of nanoparticles functionalized by gadolinium chelates are proposed: some constituted of an inorganic core that displays itself imaging properties; and some constituted of a matrix functionalized by two or more molecular agents displaying different imaging properties [74]. For the first class of materials, Roux et al. have, for example, proposed ultra-small gold nanoparticles (hydrodynamic diameter inferior to $10 \mathrm{~nm}$ ) designed

(A)

$5 \min$
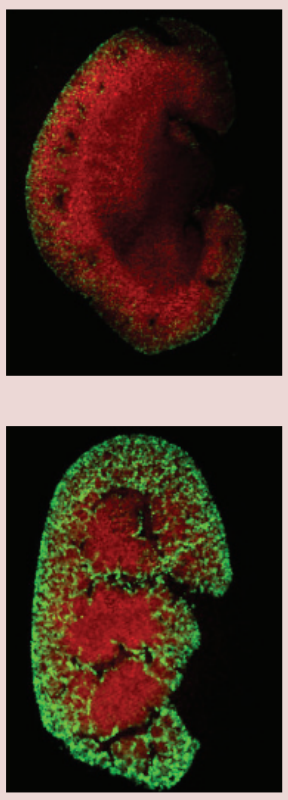

$4 \mathrm{~h}$
$30 \mathrm{~min}$
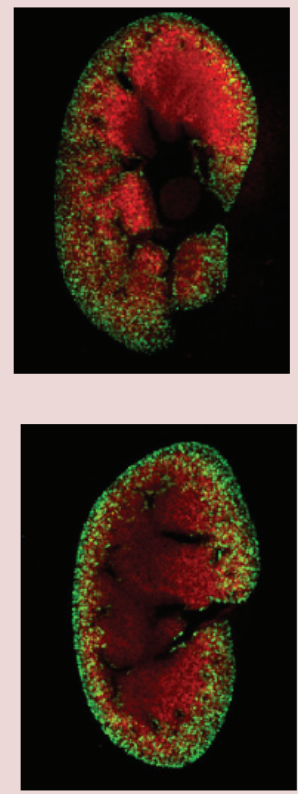

$24 \mathrm{~h}$
$1 \mathrm{~h}$
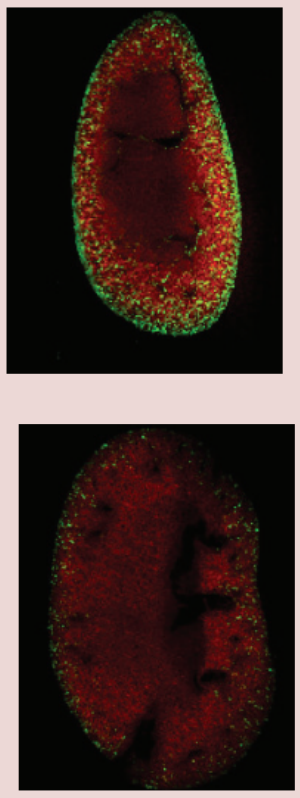

1 week

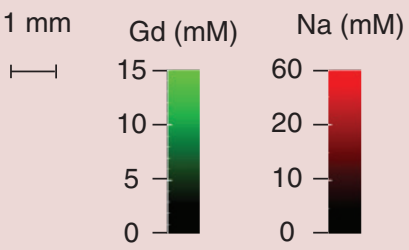

(B)

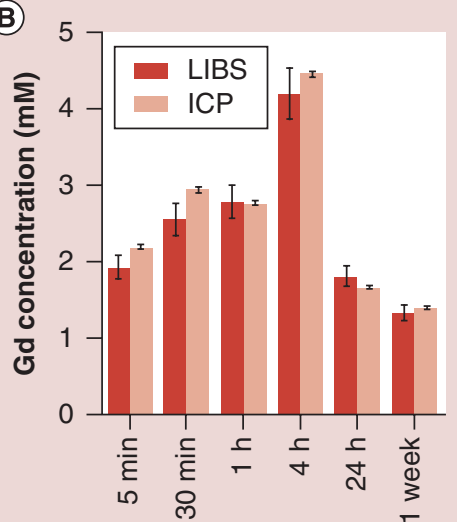

Time after injection

Figure 2. Distribution of AGuIX nanoparticles in the kidneys. (A) Quantitative mapping of gadolinium and sodium in the kidneys as a function of time. (B) Agreement between quantifications by ICP and LIBS.

ICP: Inductively coupled plasma; LIBS: Laser-induced breakdown spectroscopy.

Reproduced with permission from [68]. 

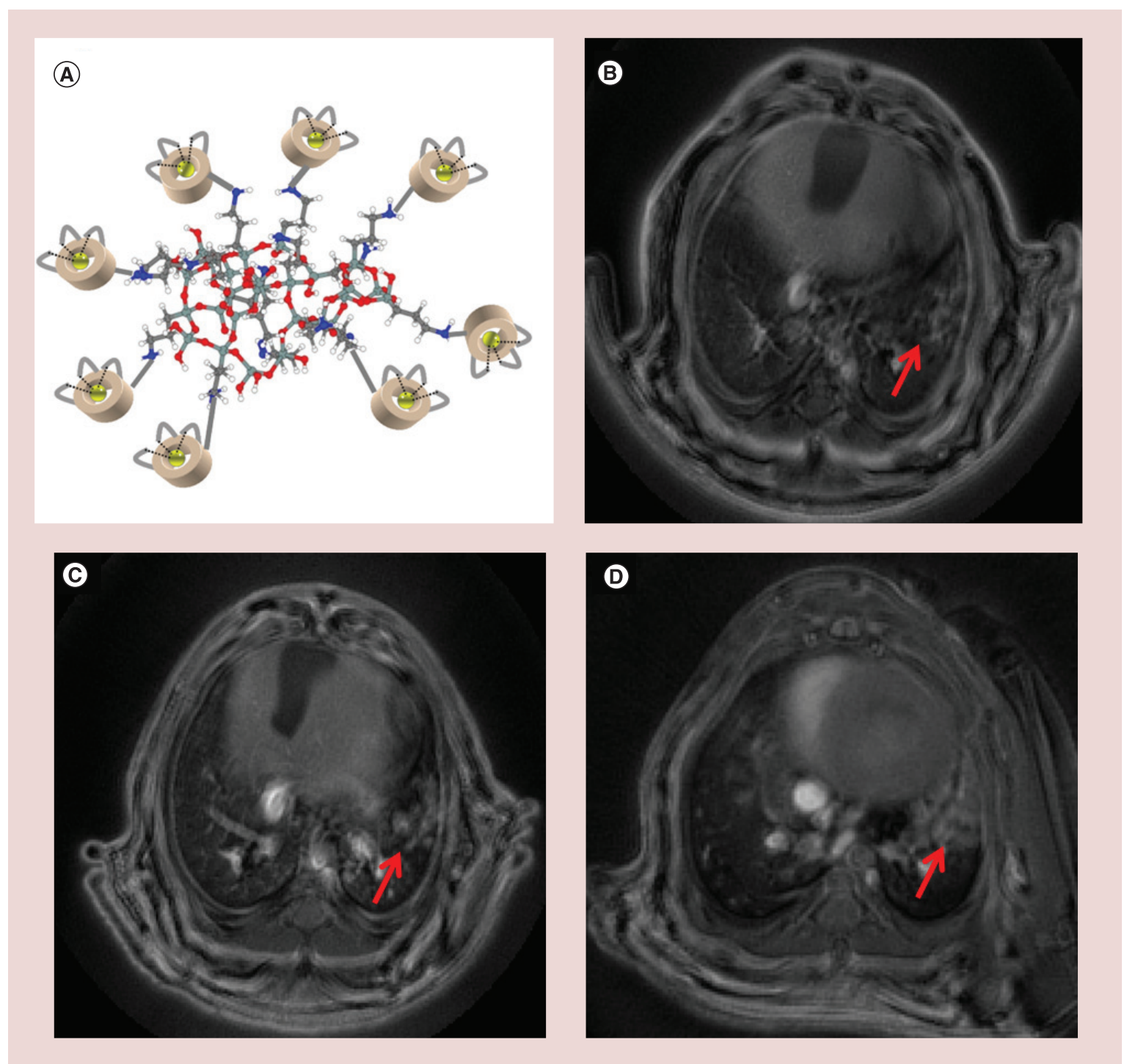

Figure 3. Detection of lung tumor by MRI. (A) Schematic representation of AGuIX with polysiloxane core and DOTA(Gd) grafted to the inorganic matrix. (B-D) UTE MRI axial slices of a lung tumor bearing mice after the orotracheal administration of AGuIX (B) 35 days, (C) 49 days and (D) 56 days after the implantation of the tumor. Red arrows indicate the tumor.

For color images please see online at http://www.futuremedicine.com/doi/full/10.2217/nnm.15.30

for renal elimination that can be used as MRI contrast agent due to gadolinium chelates, as CT contrast agent due to the gold core [75], and as SPECT imaging agent after the labeling by radioisotopes ${ }^{99 \mathrm{~m}} \mathrm{Tc}$ and ${ }^{111} \mathrm{In}$ [76]. In this case, less than $5 \%$ of the injected dose is eliminated by the feces in reason of the small size of the nanoparticle. For MRI/fluorescence bimodal imaging, quantum dots coupled to gadolinium chelates have been proposed as illustrated by Hong et al. [77] and by Zhu et al. [78]. In each case, fluorescence imaging is permitted by the crystalline core of the quantum dot and the magnetic properties by the gadolinium chelates. The nanoparticles present low cytotoxicity and interesting properties for cell labeling. Matrix displaying no imaging properties (like silica, alumina...) can also be used to gather different imaging agents as recently illustrated by our group with AGuIX nanoparticles. They can be used as imaging agents for MRI and CT, due to gadolinium chelates, for fluorescence imaging due to covalent grafting of Cyanine 5.5 (a near infrared dye) and SPECT imaging due to the labeling of DOTA derivative by ${ }^{111}$ In [79]. On this type of nanoparticles, a therapeutic modality can also be added by the addition of a photosensitizer for photodynamic therapy (PDT). The photosensitizer can be an organic molecule [80] or a complex [81]. When targeting peptides such as ATWLPPR toward neuropilin-1 (NRP-1) are grafted on the AGuIX nanoparticles designed for PDT, 
in vitro results show a photodynamic efficacy of the nanoparticles under light irradiation and an effective binding toward NRP-1 recombinant proteins. MRI suggests an effective accumulation in the tumor after intravenous injection in U87 glioblastoma-bearing rats (Figure 4) [82].

A large part of the studies currently performed on nanoparticles based on gadolinium crystalline core deals with gadolinium oxide $\left(\mathrm{Gd}_{2} \mathrm{O}_{3}\right)$. Roberts et al. [83] and Watkin and McDonald [84] were the first to show the potential of this nano-object for MRI. Following these preliminary works, our group described a reproducible and reliable synthesis of gadolinium oxide nanoparticles (size between 1 and $5 \mathrm{~nm}$ ) by modifying the polyol route [85]. To perform biological experiments, we have functionalized the cores by a polysiloxane shell to protect the oxide core and to permit further functionalization [86]. The grafting of hydrophilic PEG chains to the inorganic matrix leads to stable nanoparticles in water that can be used for in vivo experiments.
The addition of Cy 5.5 in the polysiloxane matrix for fluorescence properties permits to follow the nanoparticles by fluorescence imaging and by MRI after intravenous injection in rodents [87]. An attractive biodistribution is observed with effective renal elimination that can be changed by modifying the nature of the PEG chains grafted to the nanoparticles [19]. Engstrom et al. have confirmed the interest of gadolinium oxide for MRI [88]. In this case, the gadolinium oxide cores are capped by organic acids (citric or dimercaptosuccinic acid) that are used for further functionalization by PEG chains but unfortunately no in vivo experiment was performed. More recently, Ding et al. have studied the impact on relaxivities of a hydrophobic or a hydrophilic coating on gadolinium oxide cores [89]. For the hydrophilic coating, they choose polyvinyl pyrrolidone (PVP) and for the hydrophobic, they proceed to a first coating by hydrophobic oleic acid before adding cetyltrimethylammonium bromide. At $7 \mathrm{~T}$, they observe a longitudinal relaxivity of $12.1 \mathrm{mM}^{-1} \cdot \mathrm{s}^{-1}$ and
(A)

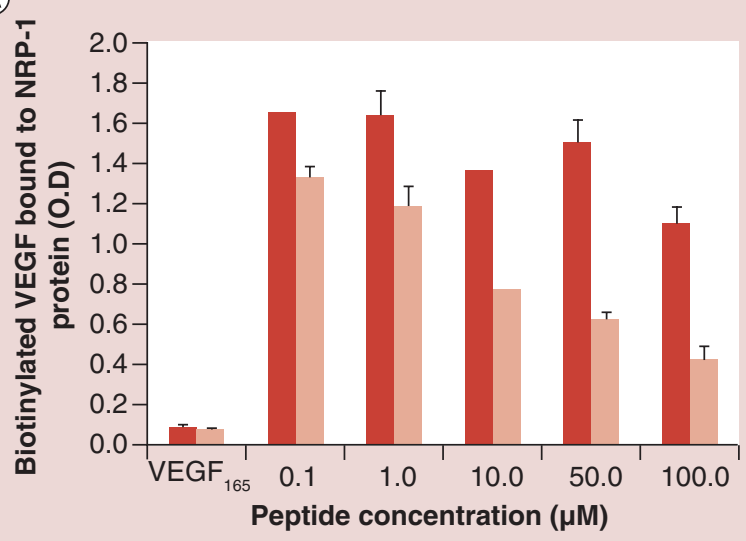

(C)

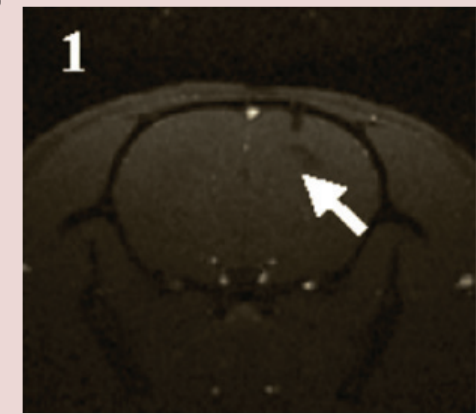

(B)
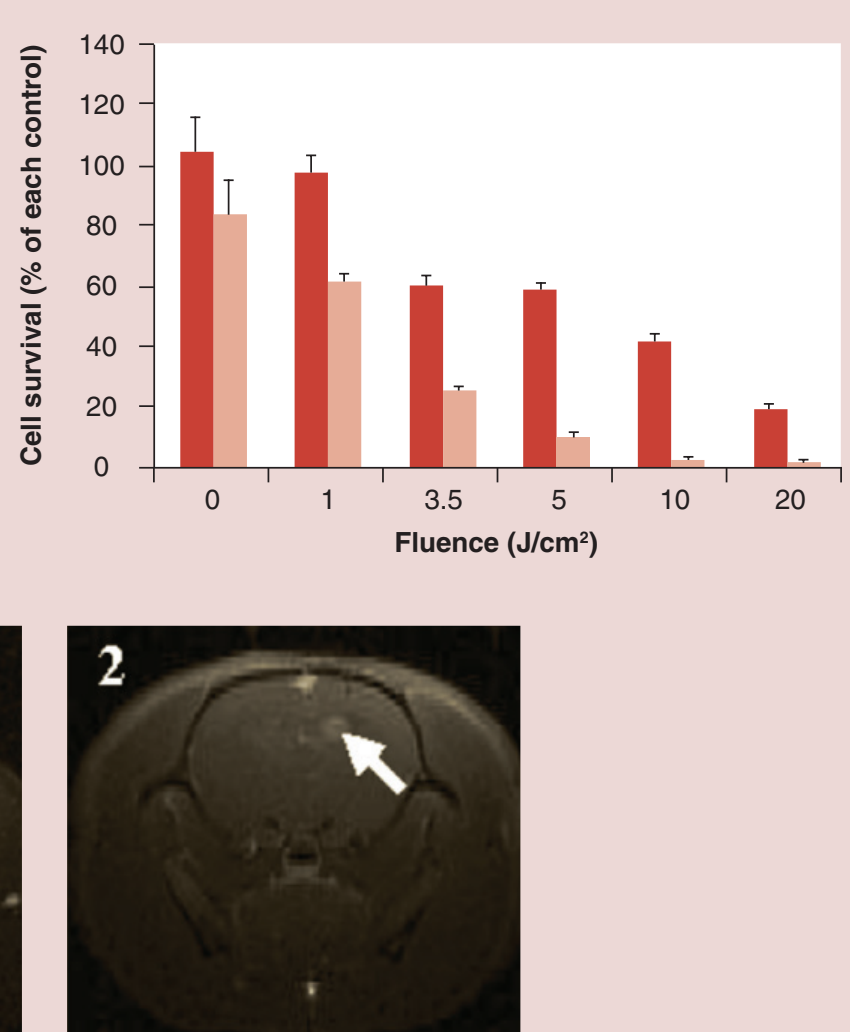

Figure 4. GuIX nanoparticles for photodynamic therapy guided by MRI. (A) Binding of untargeted AGuIX nanoparticles (dark red) and AGuIX nanoparticles functionalized by ATWLPPR (light red) toward NRP-1 recombinant protein. (B) MTT tests on MDA-MB-231 cells incubated with AGuIX functionalized by nanoparticles at two concentrations in PS (dark red: $0.1 \mu \mathrm{M}$ and light red $1 \mu \mathrm{M}$ ) exposed to increasing doses of light. (C) MRI images of the brain of U87 glioblastoma bearing rats (1) before injection of nanoparticles and (2) after injection of AGuIX functionalized by ATWLPPR. White arrows indicate the tumor. Nanoparticles containing a crystalline core constituted or doped by gadolinium.

O.D.: Optical density.

Reproduced with permission from [82]. 
$0.54 \mathrm{mM}^{-1} \cdot \mathrm{s}^{-1}$ per gadolinium for the nanoparticles coated by PVP and by oleic acid-cetyltrimethylammonium bromide, respectively. The high first value is similar to data previously obtained in the literature for such structures, the second one can be explained by the long hydrophobic chains that prevent the water molecule approaching the gadolinium of the oxide core. The nanoparticles coated by PVP were then used to image a tumor bearing mice; a high uptake in kidneys and liver is observed and only a low one is observed in the tumor.

Some other crystalline structures rich in gadolinium have also been proposed and we will focus essentially on fluoride $\left(\mathrm{GdF}_{3}\right)$ and carbonate particles $\left(\mathrm{Gd}_{2} \mathrm{O}\left(\mathrm{CO}_{3}\right)_{2}\right.$. $\mathrm{H}_{2} \mathrm{O}$ ). For $\mathrm{GdF}_{3}$ nanoparticles, Van Veggel et al. proposed a synthesis of relatively large nanoparticles by reaction of ammonium hydroxide on sodium fluoride and gadolinium nitrate in water at $75^{\circ} \mathrm{C}$. Citric acid (CA) and 2-aminoethylphosphate (AEP) were used to coat the nanoparticles leading to diameters of 129.3 and $51.5 \mathrm{~nm}$ for CA and AEP, respectively [90]. Relatively low longitudinal relaxivities are obtained for these structures (3.17 and $2.71 \mathrm{mM}^{-1} \cdot \mathrm{s}^{-1}$ for CA and AEP, respectively, at $14.1 \mathrm{~T}$ ). This study confirms that not only the gadolinium atoms present at the surface of the crystalline core contribute to the relaxation as previously shown for gadolinium oxide cores. More recently, the same group proposes the synthesis of ultra-small $\mathrm{NaGdF}_{4}$ nanoparticles to see the influence of the size on the longitudinal relaxivity [91]. Four different cores of 2.5, 4, 6.5 and $8 \mathrm{~nm}$ have been synthesized and coated by PVP during the transfer to water. As expected, the longitudinal relaxivity per gadolinium increases drastically when the size decreases from a value of $3.0 \mathrm{mM}^{-1} \cdot \mathrm{s}^{-1}$ to a value of $7.2 \mathrm{mM}^{-1} \cdot \mathrm{s}^{-1}$ per gadolinium at 1.5 T. Gadolinium carbonate nanoparticles can be obtained by addition of urea on gadolinium trichloride dissolved in ethylene glycol as shown by Kong et al., in this case it is coated by poly(acrylic acid) (PAA) [92]. By increasing the quantity of PAA added during the synthesis, the authors can monitor the size of the nanoparticles, decreasing their size by increasing the quantity of PAA (hydrodynamic diameters between 16.9 and $60.7 \mathrm{~nm}$ ). An interesting longitudinal relaxivity of $23.4 \mathrm{mM}^{-1} \cdot \mathrm{s}^{-1}$ is observed for the nanoparticles displaying a crystalline core of $2.3 \mathrm{~nm}$ and a total hydrodynamic diameter of $16.9 \mathrm{~nm}$ at $3 \mathrm{~T}$. In vivo, due to the size of the nanoparticles, an uptake in the liver and the spleen is observed but $6 \mathrm{~h}$ after injection most of the nanoparticles have been cleared from the animals.

Gadolinium ions have also been used to dope other crystalline structures to render them paramagnetic for MRI applications. In particular, gadolinium has been used to dope upconverting nanomaterials. Upconversion is a physical process consisting in the absorption of two or more photons and leading to the emission of one photon at a shorter wavelength. These materials display interesting properties for fluorescence imaging due to their absorption in the near infrared region that limits absorption and auto-fluorescence by the tissues; and their high photostability [93]. $\mathrm{NaYF}_{4}$ doped by $\mathrm{Yb}^{3+}$ and $\mathrm{Er}^{3+}$ displayed for example upconversion luminescence with maxima of emission at 520 and $650 \mathrm{~nm}$ for an excitation at $980 \mathrm{~nm}$. Zhou et al. demonstrate the interest of doping $\mathrm{NaYF}_{4}$ inorganic cores by $\mathrm{Yb}^{3+}, \mathrm{Er}^{3+}$ and $\mathrm{Gd}^{3+}$ to obtain bimodal probes (for fluorescence imaging and MRI). By labeling this nanoparticle by ${ }^{18} \mathrm{~F}$, the nanomaterial was therefore followed using PET modality [94]. In this example, the inorganic core is capped by oleic acid and the nanoparticles display hydrodynamic diameters of about $28 \mathrm{~nm}$. The $\mathrm{r}_{1}$ at $3 \mathrm{~T}$ is relatively low $\left(0.405 \mathrm{mM}^{-1} \cdot \mathrm{s}^{-1}\right)$. After intravenous injection, most of the nanoparticles present a rapid uptake in both liver and spleen (70.8 and 55.7\% of the injected dose per gram at $15 \mathrm{~min}$ after injection, respectively). As recently shown by Peng et al., this type of nanoparticle can also be used for theranostic applications and more particularly for PDT with the advantage of an excitation in the near infrared region [93]. To obtain such particles, methylene blue has been coupled to $\mathrm{NaYF}_{4}$ inorganic core doped by $\mathrm{Yb}^{3+}, \mathrm{Er}^{3+}$ and $\mathrm{Gd}^{3+}$ due to important overlap between emission spectrum of the inorganic core and the absorption spectrum of the photosensitizer. Another theranostic application has been proposed by Bu et al. by combining photothermal ablation and radiotherapy as two complementary therapeutic modalities [95]. To do this, they use an upconversion nanoparticle $\left(\mathrm{NaYbF}_{4}\right.$ inorganic core doped by $\mathrm{Er}^{3+}$ and $\mathrm{Gd}^{3+}$ ) coated by silica that is coupled to ultra-small nanoparticles of $\mathrm{CuS}$ that act as photothermal agent. The whole structure (hydrodynamic diameter close to $75 \mathrm{~nm}$ ) can produce significant cytotoxic effect after excitation at $980 \mathrm{~nm}$ and displays interesting radiosensitizing properties due to the presence of the high $\mathrm{Z}$ elements. They demonstrate the synergistic effect of radiotherapy and photothermal ablation of their materials after intratumoral injection of the nanoparticles in mice bearing $4 \mathrm{~T}_{1}$ murine breast cancer tumors.

Another example has been proposed by Fernandes et al., they synthesized Prussian blue analogues containing interstitial gadolinium cations in the inorganic matrix [96]. In this case, the inorganic core is obtained by addition of ferrous chloride to potassium hexacyanoferrate (III) and gadolinium nitrate leading to a size of about $33 \mathrm{~nm}$. A longitudinal relaxivity at $3 \mathrm{~T}$ of $38.5 \mathrm{mM}^{-1} \cdot \mathrm{s}^{-1}$ is obtained. The surface is then functionalized by avidin-Alexa fluor 488 for fluorescence prop- 
erties and by antihuman eotaxin- 3 antibody leading to important hydrodynamic diameter of $190 \mathrm{~nm}$. In vitro experiments show the interest of the nanoparticles to target the eosinophilic cell line but unfortunately no in vivo experiment has been performed.

\section{Gadolinium-based nanoparticles activated by irradiation}

In addition to its magnetic characteristics for MRI, gadolinium displays also exciting intrinsic therapeutic properties under irradiation. Two different types of irradiations can be distinguished: neutron irradiation and other types of irradiation.

\section{Irradiation by neutrons: neutron capture} therapy

This type of irradiation has been proposed relatively early to treat tumors by neutron capture therapy (NCT) [97]. The most studied compounds for NCT are ${ }^{10} \mathrm{~B}$ containing molecules that lead after neutron capture event to the deliverance of ${ }^{4} \mathrm{He}^{2+}$ and ${ }^{7} \mathrm{Li}^{3+}$ ions, compounds that dissipate their energy at short range $(\sim 5-10 \mu \mathrm{m})$ causing high damages to cells [98]. Another reason why ${ }^{10} \mathrm{~B}$ has attracted so much attention is due to its high neutron absorption cross section that is at least three orders of magnitude higher than those of elements present in the tissues (see Table 2) [99-101].

The use of gadolinium for NCT is seriously envisaged due to the high capture cross sections of ${ }^{155} \mathrm{Gd}$ and ${ }^{157} \mathrm{Gd}$ (see Table 2). Contrary to ${ }^{10} \mathrm{~B}$, the interaction of ${ }^{155,157} \mathrm{Gd}$ with neutrons leads to the emission of Auger electrons and $\gamma$-rays that display cytotoxic effect at short range and at long range, respectively [60]. Another advantage of gadolinium is that ${ }^{155} \mathrm{Gd}$ and ${ }^{157} \mathrm{Gd}$ are present at relatively high yields naturally (14.8 and $15.65 \%$ natural abundance, respectively). A relatively high optimal concentration of ${ }^{157} \mathrm{Gd}$ in tumor tissues $(50-200 \mu \mathrm{g} / \mathrm{g})$ has been determined for efficient therapeutic effect $[99,100]$. Classical MRI contrast agents have been tested for this therapeutic modality but they suffer from low uptakes in tumor after intravenous injection [100]. To increase the quantity of gadolinium delivered to the tumor, different nano-objects have been proposed. For this application, core shell nanoparticles made of gadolinium oxide core and polysiloxane shell have been synthesized $[60,88]$. Polyethylene glycol chains have been grafted on the polysiloxane shell for adapted dispersion in biological medium. The nanoparticles were internalized with EL4 cells at different concentrations before irradiation by neutrons. For 3 Gy irradiation dose, only the cells incubated with at least $0.05 \mathrm{mM}$ in gadolinium prior to the irradiation died. More recently, Aime's group proposed hydrophobic gadolinium/boron ligands that form very stable micelles in aqueous medium [98]. Cellular uptakes were tested on hepG2, B16 and U87 cells. The minimum amount of $\mathrm{B}$ for NCT has been obtained for hepG2 and U87 cells. In vivo experiments were then performed on B16 tumor bearing mice after intravenous injection of the micelles. A three times higher signal is observed in the tumor $4 \mathrm{~h}$ after the injection of the nanoparticles and a signal is still observed $24 \mathrm{~h}$ after the injection. Thanks to MRI experiment, a delay of 6 $\mathrm{h}$ after injection was determined to be adapted for neutron irradiation. An important decrease in the tumor growth is observed for the animals treated with micelles before irradiation. Unfortunately a slow regrowth of the tumor occurs at day 15 after irradiation. More recently, Yanagie et al. proposed gadolinium chelates (ProHance) entrapped in liposomes [100]. The distribution of liposomes after injection in Col 26 tumor bearing mice is then followed by MRI. Irradiation of the animals is performed between 1 and $2 \mathrm{~h}$ after the injection of the liposomes. A suppression of the tumor growth until 10 days is observed when the neutrons are used in combination with the liposomes.

These two in vivo examples emphasize the interest of MRI to determine the most suitable moment to apply irradiation.

\section{Irradiation by photons: radiosensitization}

The principle of radiotherapy is to kill cancerous cells using ionizing radiation while sparing as much as

Table 2. Various capture cross sections of specific nuclides and elements present in the tissues for thermal neutrons.

\begin{tabular}{|llll|}
\hline Nuclide & Cross-section capture value in barns & Element & Cross section capture value in barns \\
\hline${ }^{10} \mathrm{~B}$ & 3838 & $\mathrm{H}$ & 0.332 \\
\hline${ }^{149} \mathrm{Sm}$ & 42,000 & $\mathrm{C}$ & 0.0034 \\
\hline${ }^{151} \mathrm{Eu}$ & 5800 & $\mathrm{~N}$ & 1.82 \\
\hline${ }^{155} \mathrm{Gd}$ & 61,000 & $\mathrm{O}$ & $1.8 \times 10^{-4}$ \\
\hline${ }^{157} \mathrm{Gd}$ & 255,000 & $\mathrm{Na}$ & 0.43 \\
\hline${ }^{164} \mathrm{Dy}$ & 1800 & $\mathrm{Mg}$ & 0.053 \\
\hline Reproduced with permission from $[101]$. & & \\
\hline
\end{tabular}


possible the adjacent healthy tissues [44]. To minimize the damages to the healthy tissue, one of the strategies that have been developed is the use of chemical compounds that sensitize the cancerous cells to ionizing radiations (radiosensitizer) [102]. Most of the works on nanoparticles for radiosensitization have been performed on gold nanoparticles thanks to their high biocompatibility; easy synthesis and functionalization; and high density and high atomic number of gold [40].

The same type of strategy (i.e., irradiation guided by imaging) employed for NCT can be used for radiosensitization (Figure 5). Gold nanoparticles are efficient CT contrast agents but a better sensitivity can be obtained by using MRI. In this context, the addition of gadolinium chelates on gold nanoparticles is a real improvement for bimodal imaging CT/MRI or for radiotherapy guided by MRI. Some groups have developed such types of nanoparticles like Roux et al. [75], Mirkin et al. [103] or Penadés et al. [104]. In our case, the nanoparticles have been specifically designed for radiotherapy guided by MRI. As previously said, Roux et al. have specifically designed their nanoparticles for renal clearance. For the synthesis, they use a method derived from the synthesis first described by Brust et al. [105] by reducing gold salts $\left(\mathrm{HAuCl}_{4} \cdot 3 \mathrm{H}_{2} \mathrm{O}\right)$ by $\mathrm{NaBH}_{4}$ in presence of a dithiolated derivative of the diethylenetriaminepentaacetic acid. Gadolinium is then chelated by the ligands at the surface of the nanoparticles after addition of $\mathrm{GdCl}_{3} \cdot 6 \mathrm{H}_{2} \mathrm{O}$. Due to their small hydrodynamic diameter of $6.6 \pm 1.8 \mathrm{~nm}$, an almost exclusive renal elimination is observed by MRI [75], scintigraphy (after labeling by ${ }^{99 \mathrm{~m} T c}$ or ${ }^{111} \mathrm{In}$ ) [76] or inductive coupled plasma-atomic emission spectroscopy. The radiosensitizing properties of the nanoparticles have been evaluated under MRT (microbeam radiation therapy) on two tumor models: osteosarcoma and 9L glioscarcoma (9LGS) with two different types of injection - that is, intratumorally for osteosarcoma and iv. for 9LGS. For osteosarcoma, the rats only treated by MRT have an increase in lifespan (ILS) of $51.8 \%$ in comparison with untreated rats. A clear increase of the ILS is observed when the MRT is performed after the administration of the nanoparticles $(117.9 \%)$. This value is underestimated because the survey of the rats is superior to $50 \%$ when the rats were sacrificed at day 61 after implantation of the osteosarcoma tumor. For the brain tumor bearing rats, the nanoparticles have been injected by iv. and their biodistribution has been monitored by MRI. Thanks to EPR effect, a positive signal rapidly appears in the brain tumor. The higher MRI signal was observed between 3 and 7 min after the iv. injec-

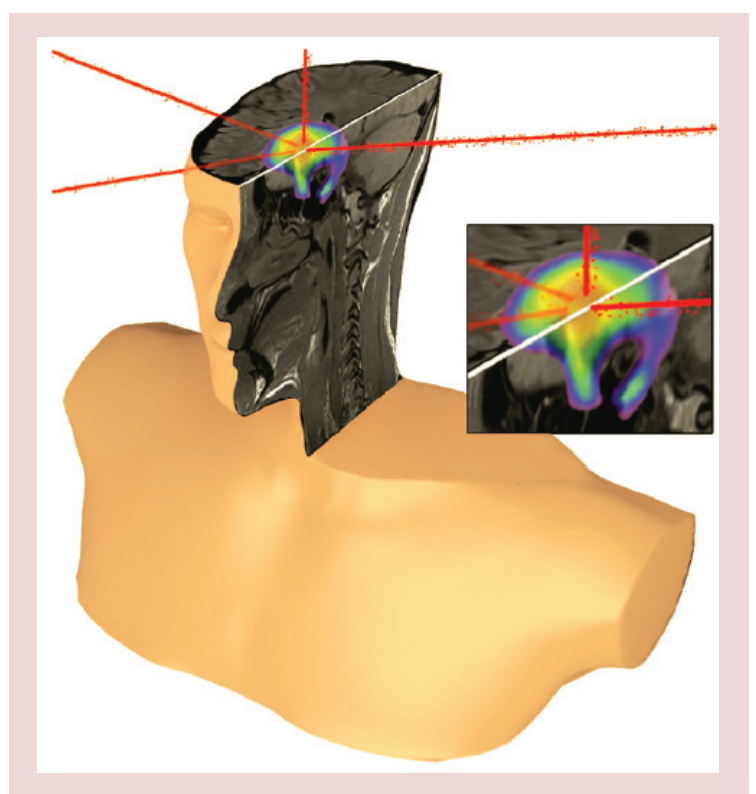

Figure 5. Schematic representation of radiotherapy guided by imaging.

Reproduced with permission from [35].

tion of the nanoparticles. This moment has been chosen to proceed to the radiotherapy. MRT only lead to an increase of the lifespan of $222 \%$ and this value is extended to $473 \%$ when the radiotherapy is performed in presence of the nanoparticles due to the radiosensitizing properties of the gold nanoparticles.

As previously described, our group has designed another type of nanoparticles specifically for biomedical applications: AGuIX nanoparticles $[35,67,79]$. These ultra-small nanoparticles made of a polysiloxane core and surrounded by gadolinium chelates (size $<5 \mathrm{~nm}$ ) have been intensively used for radiosensitization in vitro and in vivo.

In vitro, a lot of experimental conditions [35] have been tested such as varying energy of the irradiation from kiloelectron volts to higher voltages, different concentrations of nanoparticles, different types of tumor cell lines or the nature of the irradiation. As previously described by Butterworth et al. for gold nanoparticles [39,43], we observe effective radiosensitizing effect close to the K-edge of the gadolinium (in the kiloelectronvolt region where the photoelectric effect predominates) but also in the megaelectronvolt region where the Compton diffusion predominates [35]. Photon irradiation in presence of AGuIX nanoparticles has been performed on glioblastoma U-87MG and T98G cells [106], on head and neck squamous cell carcinoma SQ20B cells [107], on cervical carcinoma HeLa cells [108], on prostate DU145 and PC3 cells. In each case, significant sensitizing enhancement ratios (defined as the survival fraction (SF) ratios of the control cells (only irradiation) to those of the treated cells 
(irradiation in presence of nanoparticles)) have been observed (ranging from 1.1 to 2.5). In different studies, it has been shown that the irradiation in presence of nanoparticles induces complex damages. In particular, during the experiment on SQ20B cells, the shape of the SF was plotted against the deposited dose. The curve was fitted by the following function:

$$
S F=\exp ^{-\left[\alpha \mathrm{D}+\beta \mathrm{D}^{2}\right]}
$$

(Equation 1)

$\alpha$ : probability of lethal event; $\beta$ : sublethal events; D: irradiation dose.

Almost no change for $\beta$ is observed for irradiation in presence of nanoparticles in comparison with irradiation only ( $\beta$ varies from 0.05 to 0.03 ). On the contrary, a very significant increase of $\alpha$ is noticed when the irradiation is performed in presence of the nanoparticles ( $\alpha$ varies from 0.04 to 0.5 ) indicating a high level of lethal damages to cells. Interestingly the curve of the SF corresponding to irradiation in presence of nanoparticles is very close to those obtained with carbon ion irradiation that indicates probably a nanoscale dose deposition. To complete in vitro experiments, irradiation of cells by ions $\left(\mathrm{He}^{2+}\right.$ and $\left.\mathrm{C}^{6+}\right)$ in presence of nanoparticles has been studied [109]. In these cases, sensitizing enhancement ratios ranging from 1.1 to 1.6 have been obtained confirming the interests of the nanoparticles for different types of irradiation.

In vivo experiments have also been performed. Even if some of them have been done after intratumorally injection of the nanoparticles and have shown encouraging results with important reduction of the volume of the tumors [107], most of the studies have been performed after iv. injection for better clinical relevance. A particular attention has been paid to glioblastoma in these studies and a first proof of concept has been obtained in 2011 for 9LGS bearing rats under MRT irradiation [33]. The biodistribution followed by MRI clearly shows an uptake in the tumor in the first minutes following the administration of the nanoparticles. A signal can still be detected $24 \mathrm{~h}$ after the injection of the AGuIX due to retention in the tumors. For untreated animals, a median survival time (MeST) of 19 days is observed that is increased to 47 days for irradiated animals (ILS $=147 \%$ ). When the irradiation is triggered $5 \mathrm{~min}$ after the administration of the AGuIX nanoparticles, the MeST is shortened at 34 days (corresponding to an ILS of only $38 \%$ ). On the contrary, when the irradiation occurs $20 \mathrm{~min}$ after the iv. injection of the nanoparticles, the MeST is increased to 90 days (corresponding to an impres- sive ILS of $373 \%)$. As stated by this experiment, the delay between administration of the nanoparticles and irradiation has to be chosen carefully. The shortening of the MeST at 5 min can be explained by the MRI biodistribution that indicates that some nanoparticles are still in the healthy brain at this time (blood halflife $>5 \mathrm{~min}$ ). Contrary to molecular chelates commercially available, the nanoparticles remain for a long time in the tumor [110]. This adapted biodistribution permits to trigger the irradiation at the most adapted moment: when the nanoparticles are cleared from the healthy brain tissue but when the concentration of the nanoparticles in the tumor is still sufficient for radiosensitization. This biodistribution and the nanoscale dose deposition observed when nanoparticles are used in combination with irradiation explain the important increase of ILS. A second way of administration (by the airways) of the nanoparticles has been tested for the radiotherapy of the lung tumors [34]. The nanoparticles have been nebulized in mice bearing H358-Luc bioluminescent lung tumors. The nanoparticles labeled by a near infrared fluorophore (Cy5.5) have been detected by optical imaging and MRI. A good correlation has been obtained between the signal observed by MRI or optical imaging and the bioluminescence of the tumor and the histology [34,71]. The irradiation occurs $24 \mathrm{~h}$ after the administration of the nanoparticles. The nonirradiated and the only-irradiated mice display similar MeST of 83 and 77 days, respectively. An increase of $45 \%$ of ILS is observed when the irradiation is performed in presence of the nanoparticles (MeST of 112 days). The development of the adapted sequences for the imaging of the lungs in presence of the AGuIX permits a clear delineation of the tumor [71]. It can be used to determine the best moment for irradiation and to follow up precisely the evolution of the treatment.

\section{Conclusion \& future perspective}

Nanoparticles based on gadolinium are mainly developed for their magnetic properties as positive contrast agents for MRI. A large part of the publications in this field are dedicated to study the influence of the nanoparticle on the $r_{1}$ and unfortunately often few in vivo experiments are performed. Even if the nanoparticles can act as efficient contrast agents with relaxivities higher than commercially available molecules and effective retention in tumors due to enhanced permeability and retention effect, their development for clinical application might be compromised if they present only this imaging modality, principally due to the cost of the development of new biomedical compounds, but also the potential toxicity of nanomaterials itself and to the risk of gadolinium release for some of them. 
In our opinion, for a potential use in clinic, MRI modality has to be coupled to another modalities either for imaging or for therapeutic as illustrated in this paper. Multimodal imaging is particularly developed due to the recent release on the market of apparatus combining two imaging facilities and clearly needing the development of new imaging products and nanoparticles are well adapted to incorporate different imaging agents. In any cases, an important work will have to be performed to assess their nontoxicity and their effective elimination of the body after intravenous injection. In this context, the development of ultra-small nanoparticles that are rapidly eliminated by the kidneys seems to be the easiest way.

This paper focused particularly on nanoparticles developed for theranostic applications and more precisely on irradiation guided by MRI. In fact, as first shown by Hainfeld et al. [38] for gold nanoparticles, nanocompounds based on high atomic number atoms can be used as efficient radiosensitizers. They display effective interaction with $\mathrm{x}$-rays or secondary species that lead to nanoscale dose deposition in the close vicinity of the nanoparticle. Gadolinium can also be used for radiosensitization even if it presents lower atomic number than gold $(Z=64$ for gadolinium and 79 for gold). MRI modality is a powerful tool to localize precisely the tumor and to quantify the concentration of radiosensitizer inside it and inside the surrounding healthy tissues before irradiation. It permits to determine the most adapted moment to activate the nanoparticles by irradiation after intravenous injection and can lead to the concept of personalized medicine.

\section{Financial \& competing interests disclosure}

F Lux, O Tillement and S Roux have one patent to disclose: WO2011135101. This patent protects some of the nanoparticles described in this publication: AGuIX. The authors have no other relevant affiliations or financial involvement with any organization or entity with a financial interest in or financial conflict with the subject matter or materials discussed in the manuscript apart from those disclosed.

No writing assistance was utilized in the production of this manuscript.

\section{Open access}

This work is licensed under the Creative Commons Attribution-NonCommercial 3.0 Unported License. To view a copy of this license, visit http://creativecommons.org/licenses/bync-nd/3.0/

\section{Executive summary}

\section{Interest \& risk of gadolinium for medicine}

- More than 10 million MRI studies per year use gadolinium due to its seven unpaired electron and its slow relaxation rate.

- Gadolinium can act as an effective radiosensitizer in reason of its high atomic number that permits effective interaction with $\mathrm{x}$-rays or other types of irradiation.

- It can also be used for neutron capture therapy due to high neutron absorption cross section of gadolinium 155 and 157.

- To avoid any toxicity, no release of free gadolinium is allowed because of nephrogenic systemic fibrosis.

Main types of gadolinium-based nanoparticles

- Two main types of nanoparticles are described in this paper. Nanoparticles already considered for medical applications on which gadolinium chelates are grafted or into it they are loaded in and hybrid core shell nanoparticles made of a crystalline core based on gadolinium or doped with gadolinium $\left(\mathrm{Gd}_{2} \mathrm{O}_{3^{\prime}} \mathrm{GdF}_{3^{\prime}}\right.$ $\mathrm{NaYF}_{4}: \mathrm{Er}^{3}, \mathrm{Yb}^{3+}$ and $\mathrm{Gd}^{3+}$ among others).

Applications of gadolinium-based nanoparticles

- Many architectures are developed to increase the longitudinal relaxivity per gadolinium and per object for application as positive contrast agent in MRI.

- Many studies are devoted to multimodal imaging by addition on gadolinium-based nanoparticles of imaging agents for scintigraphy, fluorescence imaging or computed tomography.

- Growing number of publications focused on theranostic applications, gadolinium acting as MRI contrast agent and as therapeutic agent for neutron capture therapy or radiosensitization. Chemotherapy, photothermal ablation or photodynamic therapy necessitates the addition of other therapeutic agents.

Radiosensitization in presence of gadolinium-based nanoparticles

- Nanostructuration of gadolinium leads to high nanoscale dose deposition in close vicinity of the nanoparticle under irradiation.

- Radiosensitization with ultra-small gadolinium-based nanoparticles leads in vitro to complex damages.

Interest of radiotherapy guided by imaging

- Possibility to follow the biodistribution of the nanoparticles by MRI.

- Determination of the best moment for radiotherapy by imaging leading to personalized medicine. 


\section{References}

Papers of special note have been highlighted as:

- of interest; $\bullet \bullet$ of considerable interest

1 Sanchez C, Belleville P, Popall M, Nicole L. Applications of advanced hybrid organic-inorganic nanomaterials: from laboratory to market. Chem. Soc. Rev. 40, 696-753 (2011).

2 Kim BH, Hackett MJ, Park J, Hyeon T. Synthesis, characterization, and application of ultrasmall nanoparticles. Chem. Mater. 26, 59-71 (2013).

3 Yang Z, Chen CY, Roy P, Chang HT. Quantum dotsensitized solar cells incorporating nanomaterials. Chem. Comm. 47, 9561-9571 (2011).

4 Yan L, Zheng YB, Zhao F et al. Chemistry and physics of a single atomic layer: strategies and challenges for functionalization of graphene and graphene-based materials. Chem. Soc. Rev. 41, 97-114 (2012).

5 Wang ZL, Zhu G, Yang Y, Wang S, Pan C. Progress in nanogenerators for portable electronics. Materials Today 15(12), 532-543 (2012).

6 Wu Y, Wang D, Li Y. Nanocrystals from solutions: catalysts. Chem. Soc. Rev. 43, 2112-2124 (2014).

7 Sozer N, Kokini J. Nanotechnology and its applications in the food sector. Trends Biotechnol. 27(2), 82-89 (2009).

8 Etheridge ML, Campbell SA, Erdman AG, Haynes CL, Wolf SM, McCullough J. The big picture of nanomedicine: the state of investigational and approved nanomedicine products. Nanomedicine 9, 1-14 (2013).

9 Petros RA, DeSimone JM. Strategies in the design of nanoparticles for therapeutic applications. Nat. Rev. 9, 615-627 (2010).

10 Hahn MA, Singh AK, Sharma P, Brown SC, Moudgil BM. Nanoparticles as contrast agents for in-vivo bioimaging: current status and future perspectives. Anal. Bioanal. Chem. 399, 3-27 (2011).

11 Kateb B, Chiu K, Black KL et al. Nanoplatforms for constructing new approaches to cancer treatment, imaging, and drug delivery: what should be the policy? Neuroimage 54, S106-S124 (2011).

12 Liu Z, Kiessling F, Gätjens J. Advanced nanomaterials in multimodal imaging: design, functionnalization, and biomedical applications. J. Nano. Mat. 2010(ID 894303), 15 (2010).

13 Boisselier E, Astruc D. Gold nanoparticles in nanomedicine: preparations, imaging, diagnostics, therapies and toxicity. Chem. Soc. Rev. 38, 1759-1782 (2009).

14 Schladt TD, Schneider K, Child H, Tremel W. Synthesis and bio-functionalization of magnetic nanoparticles for medical diagnosis and treatment. Dalton Trans. 40, 6315-6343 (2011).

15 Zrazhevskiy P, Sena M, Gao X. Designing multifunctional quantum dots for bioimaging, detection and drug delivery. Chem. Soc. Rev. 39, 4326-4354 (2010).

16 Lee DE, Koo H, Sun IC, Ryu JH, Kim K, Kwon IC. Multifunctionnal nanoparticles for multimodal imaging and theragnosis. Chem. Soc. Rev. 41, 2656-2672 (2012).

17 Huang WY, Davis JJ. Multimodality and nanoparticles in medical imaging. Dalton Trans. 40, 6087-6103 (2011).
18 Alexis F, Pridgen E, Molnar LK, Farokhzad OC. Factors affecting the clearance and biodistribution of polymeric nanoparticles. Mol. Pharm. 5(4), 505-515 (2008).

19 Faure AC, Dufort S, Josserand V et al. Control of the in vivo biodistribution of hybrid nanoparticles with different poly(ethyleneglycol) coatings. Small 5(22), 2565-2575 (2009).

20 Choi KY, Liu G, Lee S, Chen X. Theranostic nanoplatforms for simultaneous cancer imaging and therapy: current approaches and future perspectives. Nanoscale 4, 330-342 (2012)

21 Kelkar SS, Reineke TM. Theranostics: combining imaging and therapy. Bioconj. Chem. 22, 1879-1903 (2011).

22 Shubayev VI, Pisanic II TR, Jin S. Magnetic nanoparticles for theragnostics. Adv. Drug. Deliv. Rev. 61, 467-477 (2009).

23 McCarthy JR, Weissleder R. Mulifunctional magnetic nanoparticles for targeted imaging and therapy. Adv. Drug. Deliv. Rev. 60, 1241-1251 (2008).

24 Zeng Y, Zhang D, Wu Y et al. Lipid-AuNps@PDA nanohybrid for MRI/CT imaging and photothermal therapy of hepatocellular carcinoma. ACS Appl. Mater. Interfaces. 6, 14266-14277 (2014).

25 Montalti M, Prodi L, Rampazzo E, Zaccheroni N. Dyedoped silica nanoparticles as luminescent organized systems for nanomedicine. Chem. Soc. Rev. 43, 4243-4268 (2014).

26 Kircher MF, Mahmood U, King RS, Weissleder R, Josephson L. A multimodal nanoparticle for preparative magnetic resonance imaging and intraoperative optical brain tumor delineation. Cancer Res. 63, 8122-8125 (2003).

27 De Rosales RTM. Potential clinical applications of bimodal PET-MRI or SPECT-MRI agents. J. Labelled Comp. Radiopharm. 57(4), 298-303 (2014).

28 Kryza D, Taleb J, Janier M et al. Biodistribution study of nanometric hybrid gadolinium oxide particles as a multimodal SPECT/MR/optical imaging and theragnostic agent. Bioconj. Chem. 22, 1145-1152 (2011).

29 Misri R, Saatchi K, Häfeli UO. Nanoprobes for hybrid SPECT/MR molecular imaging. Nanomedicine 7(5), 719-733 (2012).

30 Reddy LH, Arias JL, Nicolas J, Couvreur P. Magnetic nanoparticles: design and characterization, toxicity and biocompatibility, pharmaceutical and biomedical applications. Chem. Rev. 112, 5818-5878 (2012).

31 Yang HW, Liu HL, Li ML et al. Magnetic gold_nanorod/ PNIPAAmMA nanoparticles for dual magnetic resonance and photoacoustic imaging and targeted photothermal therapy. Biomaterials 34, 5651-5660 (2013).

32 Vivero-Escoto JL, Huxfords-Phillips RC, Lin W. Silicabased nanoprobes for biomedical imaging and theranostic applications. Chem. Soc. Rev. 41, 2673-2685 (2012).

33 Le Duc G, Miladi I, Alric C et al. Towards an image-guided microbeam radiation therapy using gadolinium-based nanoparticles. ACS Nano. 5, 9566-9574 (2011).

•. First in vivo radiosensitization with gadolinium-based nanoparticles injected intravenously. 
34 Dufort S, Bianchi A, Henry M et al. Nebulized gadoliniumbased nanoparticles: a theranostic approach for lung tumor imaging and radiosensitization. Small 11(2), 215-221 (2015).

- Proof of concept of lung tumor radiosensitization after administration of nanoparticles via the airways.

35 Sancey L, Lux F, Kotb S et al. The use of theranostic gadolinium-based nanoprobes to improve radiotherapy efficacy. Br. J. Radiol. 87, 20140134 (2014).

- Complete review on the results obtained with AGuIX nanoparticles.

36 Leibfarth S, Mönnich D, Welz S et al. A strategy for multimodal deformable image registration to integrate PET/ MR into radiotherapy treatment planning. Acta Oncol. 52, 1353-1359 (2013).

37 Van der Heide UA, Houweling AC, Groenendaal G, BeetsTan RGH, Lambin P. Functional MRI for radiotherapy dose painting. Magn. Reson. Imaging 30, 1216-1223 (2012).

38 Hainfeld JF, Slatkin DN, Smilowitz HM. The use of gold nanoparticles to enhance radiotherapy in mice. Phys Med. Biol. 49, N309-N315 (2004).

-• First nanoparticles (gold) used for in vivo radiosensitization.

39 Butterworth KT, McMahon SJ, Taggart LE, Prise KM. Radiosensitization by gold nanoparticles: effective at megavoltage energies and potential role of oxidative stress. Transl. Cancer Res. 2(4), 269-279 (2013).

40 Kwatra D, Venugopal A, Anant S. Nanoparticles in radiation therapy: a summary of various approaches to enhance radiosensitization in cancer. Transl. Cancer Res. 2(4), 330-342 (2013).

41 Pradhan AK, Nahar SN, Montenegro M et al. Resonant x-ray Enhancement of the Auger effect in high- $Z$ atoms, molecules, and nanoparticles: potential biomedical applications. J. Phys. Chem. A. 119, 12356-12363 (2009).

42 Miladi I, Alric C, Dufort $\mathrm{S}$ et al. The In vivo radiosensitizing effect of gold nanoparticles based MRI constrast agents. Small. 10(6), 1116-1124 (2014).

43 Butterworth K, McMahon SJ, Curell FJ, Prise KM. Physical basis and biological mechanisms of gold nanoparticles radiosensitization. Nanoscale. 4(16), 4830-4838 (2012).

44 McMahon SJ, Hyland WB, Muir MF et al. Biological consequences of nanoscale energy deposition near irradiated heavy atom nanoparticles. Sci. Rep. 1(18), 1-9 (2011).

- Discussion about the mechanisms of radiosensitization in presence of nanoparticles.

45 Sherry AD, Caravan P, Lenkinski RE. Primer on gadolinium chemistry. J. Magn. Reson. Imaging 30, 1240-1248 (2009).

46 Caravan P, Ellison JJ, McMurry TJ, Lauffer RB. Gadolinium(III) chelates as MRI contrast agents: structure, dynamics, and applications. Chem. Rev. 99, 2293-2352 (1999).

47 Caravan P. Strategies for increasing the sensitivity of gadolinium based MRI contrast agents. Chem. Soc. Rev. 35, 512-523 (2006).

48 Bulte JWM. The chemistry of contrast agents in medical magnetic resonance imaging. In: NMR in
Biomedicine. Merbach AE, Toth E (Eds). Wiley, Chichester, UK Volume 17, Issue 4, Page 210 (2001).

49 Geraldes FGC, Laurent S. Classification and basic properties of contrast agents for magnetic resonance imaging. Contrast Media Mol. Imaging 4, 1-23 (2008).

50 Terreno E, Castelli DC, Viale A, Aime S. Challenges for molecular magnetic resonance imaging. Chem. Rev. 110, 3019-3042 (2010).

51 Li Y, Beija M, Laurent $S$ et al. Macromolecular ligands for gadolinium MRI contrast agents. Macromolecules 45, 4196-4204 (2012).

52 Lim J, Turkbey B, Bernardo M et al. Gadolinium MRI contrast agents based on triazine dendrimers: relaxivity and in vivo pharmacokinetics. Bioconj. Chem. 23, 2291-2299 (2012).

53 Lux J, Chan M, Vander Elst L et al. Metal chelating crosslinkers form nanogels with high chelation stability. J. Mater. Chem. B. 1, 6359-6364 (2013).

54 Ananta JS, Godin B, Sethi R et al. Geometrical confinement of gadolinium-based contrast agents in nanoporous particles enhances $\mathrm{T}_{1}$ contrast. Nat. Nanotechnol. 5(11), 815-821 (2010).

55 Botta M, Tei L. Relaxivity Enhancement in macromolecular

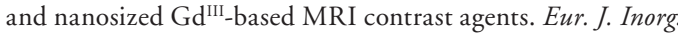
Chem. 12, 1945-1960 (2012).

56 Lux F, Roux S, Perriat P, Tillement O. Biomedical applications of nanomaterials containing gadolinium. Current Inorg. Chem. 1, 117-129 (2011).

57 Pietsch H, Jost G, Frenzel T et al. Efficacy and safety of lanthanoids as x-ray contrast agents. Eur. J. Radiol. 80(2), 349-356 (2011).

58 Preihs C, Arambula JF, Magda D et al. Recent developments in texaphyrin chemistry and drug discovery. Inorg. Chem. 52, 12184-12192 (2013).

59 Morrison DE, Aitken JB, de Jonge MD, Ioppolo JA, Harris $\mathrm{HH}$, Rendina LM. High mitochondrial accumulation of new gadolinium(III) agents within tumour cells. Chem. Commun. 50, 2252-2254 (2014).

60 Bridot JL, Dayde D, Rivière C et al. Hybrid gadolinium oxide nanoparticles combining imaging and therapy. J. Mat. Chem. 19, 2328-2335 (2009).

61 Thomsen D. Nephrogenic systemic fibrosis: a serious late adverse reaction to gadodiamide. Eur. Radiol. 16, 2619-2621 (2006).

62 Stasiuk GJ, Long NJ. The ubiquitous DOTA and its derivatives: the impact of 1,4,7,10-tetraazacyclododecane1,4,7,10-tetraacetic acid on biomedical imaging. Chem. Commun. 49, 2732-2746 (2013).

63 Davies GL, Kramberger I, Davies JJ. Environmentally responsive MRI contrast agents. Chem. Commun. 49, 9704-9721 (2013).

64 Shokrollahi H. Contrast agents for MRI. Mat. Sci. Eng. C. 33, 4485-4497 (2013).

65 Choi HS, Liu W, Misra P et al. Renal clearance of quantum dots. Nat. Biotechnol. 25(10), 1165-1170 (2007).

- Interest of ultrasmall nanoparticles for renal elimination. 
66 Choi HS, Liu WH, Liu FB et al. Design considerations for tumour-targetednanoparticles. Nat Nanotechnol. 5(1), 42-47 (2010).

67 Mignot A., Truillet C, Lux F et al. A top-down synthesis route to ultrasmall multifunctional Gd-based silica nanoparticles for theranostic applications. Chem. Eur. J. 19, 6122-6136 (2013).

68 Sancey L, Motto-Ros V, Busser B et al. Laser spectrometry for multi-elemental imaging of biological tissues. Sci. Rep. 4, 6065 (2014).

69 Bianchi A, Lux F, Tillement O, Crémillieux Y. High resolution contrast enhanced lung MRI in mice using ultra-short echo time radial imaging and intratracheally administrated Gdbased contrast agent. Mag. Res. Med. 70, 1419-1426 (2013).

70 Bianchi A, Dufort S, Lux F et al. Quantitative biodistribution and pharmacokinetics of multimodal gadolinium-based nanoparticles for lungs using ultrashort TE MRI. Magn. Reson. Mater. Phy. 27(4), 303-316 (2014).

71 Bianchi A, Dufort S, Lux F et al. Targeting and in vivo imaging of non-small-cell lung cancer using nebulized multimodal contrast agents. Proc Natl Acad. Sci. USA 111(25), 9247-9252 (2014).

-• $\quad$ First MRI positive contrast agent based on nanoparticle for lung imaging.

72 Pagel MD. The hope and hype of multimodality imaging contrast agents. Nanomedicine 6(6), 945-948 (2011).

73 Louie A. Multimodality imaging probes: design and challenges. Chem Rev 110, 3146-3195 (2010).

74 Cormode DP, Sanchez-Gaytan BL, Mieszawska AJ, Fayad ZA, Mulder WJM. Inorganic nanocrystals as contrast agents in MRI: synthesis, coating and introduction of multifunctionnality. NMR Biomed. 26, 766-780 (2013).

75 Alric C, Taleb J, Le Duc G et al. Gadolinium chelate coated nanoparticles as contrast agents for both x-ray computed tomography and magnetic resonance imaging. J. Am. Chem. Soc. 130(18), 5908-5915 (2008).

76 Alric C, Miladi I, Kryza D et al. The biodistribution of gold nanoparticles designed for renal clearance. Nanoscale 5 , 5930-5939 (2013)

77 Park J, Bhuniya S, Lee $\mathrm{H}$ et al. A DTTA-ligated uridinequantum dot conjugate as a bimodal contrast agent for cellular imaging. Chem. Commun. 48, 3218-3220 (2012).

78 Lin B, Yao X, Zhu Y, Shen J, Yang X, Li C. Multifunctionnal gadolinium-labelled silica-coated core/shell quantum dots for magnetic resonance imaging of cancer cells. RSC Adv. 4, 20641-20648 (2014).

79 Lux F, Mignot A, Mowat P et al. Ultrasmall rigid platforms as multimodal probes for medical applications. Angew. Chem. Int. Ed. 51, 12299-13303 (2011).

80 Benachour $\mathrm{H}$, Bastogne $\mathrm{T}$, Toussaint $\mathrm{M}$ et al. Real-time monitoring of photocytotoxicity in nanoparticles-based photodynamic therapy: a model-based approach. PLoS ONE 7(11), e48617 (2012).

81 Truillet C, Lux F, Moreau J et al. Bifunctionnal polypyridyl$\mathrm{Ru}(\mathrm{II})$ complex grafted onto gadolinium-based nanoparticles for MR-imaging and photodynamic therapy. Dalton Trans. 42, 12410-12420 (2013).
82 Benachour $\mathrm{H}$, Sève $\mathrm{A}$, Bastogne $\mathrm{T}$ et al. multifunctionnal peptide-conjugated hybrid silica nanoparticles for photodynamic therapy and MRI. Theranostics 2(9), 889-904 (2012).

83 Roberts D, Zhu WL, Frommen CM, Rosenzweig Z. Synthesis of gadolinium oxide magnetoliposomes for magnetic resonance imaging. J. App. Phys. 87(9), 6208-6210 (2000).

84 McDonald MA, Watkin KL. Small particulate gadolinium oxide albumin microspheres as multimodal contrast and therapeutic agents. Investig. Radiol. 38(6), 305-310 (2003).

85 Bazzi R, Flores MA, Louis C et al. Synthesis and properties of europium-based phosphors on the nanometer scale: $\mathrm{Eu}_{2} \mathrm{O}_{3}, \mathrm{Gd}_{2} \mathrm{O}_{3}:$ Eu and $\mathrm{Y}_{2} \mathrm{O}_{3}$ :Eu. J. Colloid Interface Sci. 273, 191-197 (2004).

86 Louis C, Bazzi R, Marquette CA et al. Nanosized hybrid particles with double luminescence for biological labelling. Chem. Mater. 17, 1673-1682 (2005).

87 Bridot JL, Faure AC, Laurent $S$ et al. Hybrid gadolinium oxide nanoparticles: multimodal contrast agents for in vivo imaging. J. Am. Chem. Soc. 129, 5076-5084 (2007).

88 Engstrom M, Klasson A, Pedersen H, Vahlberg C, Kall PO, Uvdal K. High proton relaxivity for gadolinium oxide nanoparticles. Magn. Reson. Mater. Phys. 19, 180-186 (2006).

89 Fang J, Chandrasekharan P, Liu XL et al. Manipulating the surface coating of ultra-small $\mathrm{Gd}_{2} \mathrm{O}_{3}$ nanoparticles for improved T-1-weighted MR imaging. Biomaterials. 35(5), 1632-1642 (2014).

90 Evanics E, Diamente PR, van Veggel FCJM, Stanisz GJ, Prosser RS. Water-soluble $\mathrm{GdF}_{3}$ and $\mathrm{GdF}_{3} / \mathrm{LaF}_{3}$ nanoparticles-physical characterization and NMR relaxation properties. Chem. Mater. 18, 2499-2505 (2006).

91 Johnson NJJ, Oakden W, Stanisz GJ, Prosser RS, van Veggel FCJM. Size-tunable, ultrasmall $\mathrm{NaGdF}_{4}$ nanoparticles: insights into their $\mathrm{T}_{1} \mathrm{MRI}$ contrast enhancement. Chem. Mater. 23, 3714-3722 (2011).

92 Liang G, Cao L, Chen $\mathrm{H}$ et al. Ultrasmall gadolinium hydrated carbonate nanoparticle: an advanced $\mathrm{T}_{1} \mathrm{MRI}$ contrast agent with large longitudinal relaxivity. J. Mat. Chem. B. 1, 629-638 (2013).

93 Chen F, Zhang S, Bu W et al. A uniform sub-50 nm-sized magnetic/upconversion fluorescent bimodal imaging agent capable of generating singlet oxygen by using a $980 \mathrm{~nm}$ Laser. Chem. Eur. J. 18, 7082-7090 (2012).

94 Zhou J, Yu M, Sun Y et al. Fluorine-18-labeled $\mathrm{Gd}^{3+} / \mathrm{Yb}^{3+} /$ $\mathrm{Er}^{3+}$ co-doped $\mathrm{NaYF}_{4}$ nanophosphors for multimodality PET/MR/UCL imaging. Biomaterials 32, 1148-1156 (2011).

95 Xiao Q, Zheng X, Bu W et al. A core/satellite multifunctionnal nanotheranostic for in vivo imaging and tumor eradication by tadiation/photothermal synergistic therapy. J. Am. Chem. Soc. 135, 13041-13048 (2013).

96 Dumont MF, Hoffman HA, Yoon PRS et al. Biofunctionnalized gadolinium-containing prussian blue nanoparticles as multimodal molecular imaging agents. Bioconj. Chem. 25, 129-137 (2014). 
Locher GL. Biological effects and therapeutic possibilities of neutrons. Am. J. Roentgenol. Radium Ther. 36, 1-13 (1936). Geninatti-Crich S, Alberti D, Szabo I et al. MRI-guided neutron capture therapy by use of a dual gadolinium/boron agent targeted at tumour cells through upregulated lowdensity lipopotein transporters. Chem. Eur. J. 17, 8479-8486 (2011).

- Gadolinium/boron nano-object for neutron capture therapy.

99 Hwang KC, Lai PD, Chiang CS, Wang PJ, Yuan CJ. Neutron capture nuclei-containing carbon nanoparticles for destruction of cancer cells. Biomaterials 31, 8419-8425 (2010).

100 Dewi N, Yanagie H, Zhu H et al. Biomed. Pharmacother. 67, 451-457 (2013).

101 Soloway AH, Tjarks W, Barbum BA et al. The chemistry of neutron capture theory. Chem. Rev. 98, 1515-1562 (1988).

102 Butterworth KT, Wyer JA, Brennan-Fournet M et al. Variation if strand break yield for plasmid DNA irradiated with high-Z metal. Radiat. Res. 170(3), 381-387 (2008).

103 Song Y, Xu X, MacRenaris KW, Zhang WQ, Mirkin CA, Meade TJ. Multimodal gadolinium-enriched dna-gold nanoparticle for cellular imaging. Angew. Chem. Int. Ed. 48, 9143-9147 (2009).
104 Marradi M, Alcantara D, Martinez de le Fuente J, Garcia Martin ML, Cerdan S, Penadès S. Paramagnetic Gd-based gold gluconanoparticles as probes for MRI: tuning relaxivities with sugars. Chem. Commun. 26, 3922-3924 (2009).

105 Brust M, Fink J, Bethell D, Schiffrin DJ, Kiely C. Synthesis and reactions of functionalized gold nanoparticles. J Chem Soc, Chem. Commun. 16, 1655-1656 (1995).

106 Mowat P, Mignot A, Rima W et al. In vitro radiosensitizing effects of ultrasmall gadolinium based particles on tumour cells. J. Nanosci. Nanotechnol. 11, 7833-7839 (2011).

107 Miladi I, Aloy MT, Armandy E et al. Combining ultrasmall gadolinium-based nanoparticles with photon irradiation overcomes radioresistance of head and neck suqamous cell carcinoma. Nanomedicine 11(1), 247-257 (2015).

108 Luchette M, Korideck H, Makrigiorgos M, Tillement $\mathrm{O}$, Berbeco R. Radiation dose enhancement of gadolinium-based AGuIX nanoparticles on HeLa cells. Nanomedicine 10(8), 1751-1755 (2014).

109 Porcel E, Tillement O, Lux F et al. Gadolinium-based nanoparticles to improve hadrontherapy performances. Nanomedicine 10(8), 1601-1608 (2014).

110 Le Duc G, Roux S, Paruta-Tuarez A et al. O. Advantages of gadolinium based ultrasmall nanoparticles vs molecular chelates for radiotherapy guided by MRI for glioma treatment. Cancer Nanotechnol. 5, 4 (2014). 